\title{
O CASO DAMIÃO XIMENES, A LEI DE REFORMA PSIQUIÁTRICA E OS AVANÇOS EM SAÚDE MENTAL NO BRASIL
}

\author{
Jéssica Santos Machado ${ }^{1}$; Márcia Costa Misi² \\ 1. Bolsista PIBIC/FAPESB, Graduanda em Direito, Universidade Estadual de Feira de Santana, e-mail: \\ jessicamelsirius@gmail.com \\ 2. Orientadora, Departamento de Ciências Sociais Aplicadas, Universidade Estadual de Feira de Santana, e-mail: \\ marciamisi@gmail.com
}

PALAVRAS-CHAVE: CIDH; Lei de Reforma Psiquiátrica; Saúde Mental.

\section{INTRODUÇÃO}

O triste cenário enfrentado pelas pessoas que possuíam algum transtorno mental grave no Brasil, sobretudo na segunda metade do século XX, era motivo de incômodo para médicos psiquiatras e familiares. Os primeiros enfrentavam condições precárias de trabalho em clínicas mal preparadas para receber os pacientes. Os segundos sofriam em ter que deixar seus entes queridos à mercê dos escassos cuidados dos profissionais médicos e enfermeiros das instituições.

A crítica ao modelo hospitalocêntrico, ou seja, à centralização e internamento compulsório e indiscriminado dos pacientes psiquiátricos em hospitais surge no Brasil por volta do ano 1978, através do Movimento dos Trabalhadores em Saúde Mental. O movimento, formado por associações de familiares desses pacientes, juntamente com profissionais que trabalhavam direta ou indiretamente com essas pessoas, trazia a denúncia dos maus tratos e atrocidades cometidas dentro dos manicômios, ou hospitais psiquiátricos. (BRASIL, 2005)

O movimento por um país livre de instituições psiquiátricas encarceradoras de seus pacientes toma forma e é discutido em diversos encontros entre a comunidade e profissionais da área. Os encontros importantes para o amadurecimento do enfrentamento da doença psiquiátrica no Brasil foram: em 1987, em Bauru, São Paulo, o II Congresso Nacional de Trabalhadores em Saúde Mental; em 1990, a Conferência de Caracas; e em Dezembro de 1992, a II Conferência Nacional de Saúde Mental, no Rio de Janeiro.

Em 1989 deu entrada no Congresso Nacional o Projeto de Lei do Deputado Paulo Delgado (PT/MG), Projeto de Lei 3.657/89, propondo a regulamentação dos direitos da pessoa com transtornos mentais e a extinção progressiva dos manicômios. O Projeto de Lei conferiu uma dimensão nacional às medidas que já estavam sendo tomadas em lugares pontuais no Brasil e deu corpo ao Movimento Antimanicomial no Brasil. O Projeto foi derrubado em 1995, mas em seu lugar e de total inspiração neste, o Projeto do Senador Lucídio Portella culmina, doze anos após o projeto do deputado Delgado, na Lei 10.216/2011 mais conhecida como Lei de Reforma Psiquiátrica.

A chamada de "mercantilização da loucura", onde as instituições privadas recebiam do Estado, na figura do município, para manter esses pacientes internados, foi uma das situações denunciadas por Austregésilo Carrano Bueno, usuário de maconha que foi internado em uma dessas clínicas, em seu livro autobiográfico Canto dos Malditos, que inspirou o filme Bicho de Sete Cabeças da diretora Laís Bodanzky e roteiro de Luiz Bolognesi. Além da mercantilização e interesse em manter os pacientes nos hospitais psiquiátricos para receber mais verbas do município, o livro traz uma denúncia sobre os métodos e a violência institucional praticada por médicos e enfermeiros, no qual o hospital possuía áreas de isolamento para o "castigo" dos pacientes, além dos maus tratos físicos como banhos gelados, instalações degradantes à condição humana e alimentação básica deficiente, e psicológicos como pressões produzidas pelos próprios médicos e enfermeiros, ao tratarem os pacientes em termos semelhantes a animais. 
Em uma dessas instituições privadas credenciada ao Sistema Único de Saúde, a Casa de Repouso Guararapes, foi internado Damião Ximenes. Damião sofreu abusos físicos gravíssimos que o levaram a óbito em uma clínica Psiquiátrica do Município de Sobral, no interior do Ceará, em Outubro de 1999. Sua irmã, indignada com o tratamento desumano recebido por ele, resolveu recorrer à justiça brasileira, mas sem uma resposta digna da memória de seu irmão submeteu o caso à Corte Internacional de Direitos Humanos para que o Estado pagasse por seus erros.

Na Corte Internacional de Direitos Humanos, o Caso Damião Ximenes representou a primeira condenação no âmbito dos direitos das pessoas portadoras de transtornos mentais e a primeira condenação formal do Brasil na Corte.

\section{METODOLOGIA}

Foram levadas em consideração a Lei 10.216/2001, também conhecida como Lei de Reforma Psiquiátrica, além da Convenção Interamericana para a Eliminação de Todas as Formas de Discriminação contra as Pessoas Portadoras de Deficiência. O estudo foi realizado por meio da investigação bibliográfica sobre Direito Internacional dos Direitos Humanos (em livros, jornais e textos especializados), nos limites do escopo de investigação proposto.

\section{DISCUSSÃO}

A decisão da Corte, sobretudo no âmbito de garantir indenização aos familiares e outras vítimas da mesma clínica, deu força para que outras entidades pudessem cobrar um tratamento adequado e respeitoso às garantias individuais. O Estado Brasileiro tem a obrigação de reparar qualquer dano cometido por sua negligência, de modo que a Sentença foi de total importância para que isso acontecesse. Afinal, está na Constituição de 1988, em seu artigo $5^{\circ}$, todo o rol de garantias individuais que devem ser respeitadas pelo Estado Brasileiro.

A partir da denúncia e indignação de Irene Lopes, irmã de Damião, foi possível a descoberta de diversos outros casos de maus tratos na mesma clínica, assim como o modo pelo qual os pacientes eram mantidos na clínica por mais tempo que deveriam, garantindo mais diárias pagas pelo Estado.

Nesse sentido, o Estado Brasileiro adotou diversas medidas a nível nacional para tentar reparar os danos causados aos pacientes portadores de doenças mentais por sua negligência. Dentre as que foram destacadas na Sentença exarada pela Corte, em 2006, encontram-se: "a aprovação da Lei $\mathrm{n}^{\mathrm{o}}$ 10.216, em 2001, conhecida como "Lei de Reforma Psiquiátrica"; a realização do seminário sobre "Direito à Saúde Mental - Regulamentação e aplicação da Lei n ${ }^{\circ}$ 10.216", em 23 de novembro de 2001"; (CIDH. CASO XIMENES LOPES VS. BRASIL. SENTENÇA, 2006). A Sentença ainda destacou a "a criação a partir de 2002 do Programa Nacional de Avaliação dos Serviços Hospitalares Psiquiátricos [...] e a consolidação em 2004 do Fórum de Coordenadores de Saúde Mental. (CIDH. CASO XIMENES LOPES VS. BRASIL. SENTENÇA, 2006).

Dentre as medidas tomadas pelo governo, está a promulgação da Lei de Reforma Psiquiátrica, em Abril de 2001. A Lei de Reforma Psiquiátrica foi um grande passo na luta pelo tratamento psiquiátrico de qualidade no momento em que garante, sob a forma escrita, os direitos do paciente com transtornos mentais. A Lei permitiu a criação da Política de Saúde Mental, que promove a redução controlada dos leitos psiquiátricos e incentivando o retorno às residências e a reintegração do paciente psiquiátrico na sociedade.

Em adição, a política trouxe uma nova abordagem no tratamento dos pacientes ao aproximar-se do território do paciente, criando uma rede de dispositivos capazes de dar a atenção básica necessária e dependendo da gravidade do caso, direcionados para uma rede de maior suporte. O internamento que acontecia de forma indiscriminada, depois da Lei só é permitido em três situações, de forma voluntária, involuntária em casos gravosos e de maneira 
compulsória no caso dos internamentos judiciais. Ainda assim, o internamento é medida extrema, recomendada apenas em casos em que os familiares não possuam a capacidade de monitoramento ou em casos nos quais mereçam uma atenção hospitalar.

Em 2003 foi instituído o "Programa de volta para casa" através da Lei Federal 10.708/2003, qual iniciou um processo de reinserção dos pacientes de longo período de internamento em hospitais psiquiátricos na sociedade. $\mathrm{O}$ programa fornecia a reabilitação dessas pessoas que foram vítimas de tratamentos desumanos nas instituições, provendo também uma quantia mensal como forma de manutenção e indenização pelos danos sofridos. O programa está de acordo com o que a Lei de Reforma Psiquiátrica propôs: o retorno gradual às residências e a desinstitucionalização do atendimento psiquiátrico.

No ano 2000, depois do descredenciamento da Casa de Repouso Guararapes, o município de Sobral deu início a implementação da Rede de Atenção Integral à Saúde Mental (RAISM), que viria descentralizar o atendimento hospitalar aos pacientes psiquiátricos.

Em Sobral, Ceará, foram adotas as seguintes medidas elencadas pela Sentença da Corte: "foi assinado no ano 2000 um convênio entre o Programa Saúde na Família e a Equipe de Saúde Mental do Município de Sobral; e foram criados uma Unidade de Internação Psiquiátrica no Hospital Dr. Estevão da Ponte do Município de Sobral; [...]” (CIDH. CASO XIMENES LOPES VS. BRASIL. SENTENÇA, 2006).

Os primeiros passos à Reforma Psiquiátrica no município, que dentre as outras ações, promoveu a capacitação de profissionais, a comunicação com outros municípios para a troca de experiências, uma maior proximidade com a comunidade, com a implantação dos CAPS e outros modos de intervenção na atenção básica. Em dados divulgados no jornal eletrônico Diário do Nordeste, em 2010, 48 equipes de saúde atuam na Rede de Atenção Integral à Saúde Mental (RAISM), sendo essas equipes distribuídas entre 28 centros de saúde da família, 15 na sede e 13 nos distritos, se tornando referência nacional. (DIÁRIO DO NORDESTE, 2010)

\section{CONSIDERAÇÕES FINAIS}

É inegável que as investigações sobre o caso de Damião Ximenes aconteceram em um momento de transformação dos modelos de tratamentos psiquiátricos no país. Porém, o período de doze anos para que a Lei do Deputado Paulo Delgado fosse finalmente promulgada, dois anos depois da morte de Damião, deixa claro que se trata de uma resposta do governo brasileiro de retratação não apenas com o caso, mas com todos os pacientes que foram vítimas dos maus tratos nessas clínicas.

Adiciona-se a isso, a grande repercussão que o caso teve na época, graças a incansável luta da irmã de Damião, Irene Lopes e sua vontade de não deixar impune o Estado, então responsável pela integridade física dos cidadãos.

Muitas mudanças já estavam acontecendo no Brasil com a intenção de amenizar os internamentos, mas os projetos ocorriam de forma nuclear, com variantes em cada comunidade. A Lei veio trazer respaldo e implantar uma política pública de reintegração dos pacientes portadores de transtornos mentais, modelo idealizado ainda na segunda metade do século XX.

As mudanças, por sua vez, não foram impostas como a solução definitiva para os casos. Há ainda muito o que se estudar e discutir a respeito das técnicas de abordagem aos indivíduos com transtornos mentais. Um dos problemas enfrentados pela política de retorno ao meio social, por exemplo, é o preconceito que ainda existe na população brasileira e a dificuldade de reintegração dessas pessoas. Alguns familiares não aceitam o retorno, o que interrompe o processo de reabilitação, mantendo esses indivíduos ainda sob o domínio hospitalar. 
Outro problema é que o Sistema Único de Saúde brasileiro não é capaz de absorver a demanda de pacientes, fazendo que boa parte dos doentes fiquem desassistidos por falta de médicos especializados e atendimento regular.

A doença mental é ainda motivo de inquietação entre os estudiosos, que estão sempre a discutir os melhores tratamentos e ressocialização dos indivíduos acometidos por ela. $\mathrm{O}$ Brasil avançou com a proposta de desinstitucionalização, mas é preciso mais esforços para que os pacientes com transtornos mentais tenham de volta a sua qualidade de vida.

\section{REFERÊNCIAS}

BORGES, Nadine. Damião Ximenes: Primeira Condenação do Brasil na Corte Interamericana de Direitos Humanos. Rio de Janeiro: Revan, 2009.

BRASIL. Lei 10.216, de 6 de abril de 2001. Dispõe sobre a proteção e os direitos das pessoas portadoras de transtornos mentais e redireciona o modelo assistencial em saúde mental. In: Diário Oficial da União, Brasília, DF, 9 abr. 2001. Seção 1. Disponível em:< http://www.planalto.gov.br/ccivil_03/leis/LEIS_2001/L10216.htm>. Acesso em Março 2016 BRASIL. Ministério da Saúde. Secretaria de Atenção à Saúde. DAPE. Coordenação Geral de Saúde Mental. Reforma psiquiátrica e política de saúde mental no Brasil. Documento apresentado à Conferência Regional de Reforma dos Serviços de Saúde Mental : 15 anos depois de Caracas. OPAS. Brasília, novembro de 2005. Disponível em: < http://bvsms.saude.gov.br/bvs/publicacoes/Relatorio15_anos_ Caracas.pdf >. Acesso em Março 2016.

CORTE INTERAMERICANA DE DIREITOS HUMANOS. Caso Ximenes Lopes vs. Brasil. Sentença de 04 de junho de 2006. Mérito, Reparação e Custas. Disponível em http://www.corteidh.or.cr/docs/casos/articulos/seriec_149_por.pdf. Acesso em Junho 2016.

LIMA, Aluísio F. de; PONTES, Maria V. A. O Caso Damião Ximenes Lopes e a primeira condenação internacional do Brasil na Corte Interamericana de Direitos Humanos. Disponível em: < https://www.google.com.br/url?sa=t\&rct =j\&q=\&esrc=s\&source=web\&cd $=4 \& \mathrm{cad}=$ rja\&uact=8\&ved=0ahUKEwjH193KqpfOAhUQPJAKHdmNAhoQFggtMAM\&url= http\%3A\%2F\%2Fincubadora.periodicos.ufsc.br\%2Findex.php\%2Fcbsm\%2Farticle\%2Fdown load\%2F3076\%2F4323\&usg=AFQjCNHjsK0eAgc64LbEK1A11vzSEaAiw\&bvm=bv. 128617 741,d.Y2I > Acesso em Maio 2016.

MONTEIRO, Rita Maria Paiva. "Dizem que sou louco" : o caso Damião Ximenes e a reforma psiquiátrica em Sobral/CE. Tese de Doutorado - Universidade Federal do Ceará, Centro de Humanidades, Departamento de Ciências Sociais, Programa de Pós-Graduação em Ciências Sociais, $\quad$ Fortaleza, 2015. Disponível em:< http://www.repositorio.ufc.br/bitstream/riufc/12659/1/2015_tese_rmpmonteiro.pdf>. Acesso em Maio 2016.

SILVA, Martinho B. B. e . O "Caso Damião Ximenes": a constituição de agentes e agências estatais através da vocalização pública do sofrimento Disponível em: < http://www.abant.org.br/conteudo/ANAIS/CD_Virtual_26_RBA/grupos_de_trabalho/trabalho s/GT\%2008/martinho\%20braga\%20batista\%20e\%20silva.pdf >. Acesso em Maio 2016.

SOBRAL É REFERENCIA EM CAPS. 02/11/2010. Disponível em:< http://diariodonordeste.verdesmares.com.br/cadernos/regional/sobral-e-referencia-em-caps1.637410>. Acesso em Junho 2016. 